\title{
The serum angiotensin converting enzyme and lysozyme levels in patients with ocular involvement of autoimmune and infectious diseases
}

\author{
Ozlem Sahin ${ }^{*}$, Alireza Ziaei ${ }^{2}$, Eda Karaismailoğlü ${ }^{3}$ and Nusret Taheri ${ }^{4}$
}

\begin{abstract}
Background: Increased serum levels of angiotensin converting enzyme and lysozyme are considered as inflammatory markers for diagnosis of sarcoidosis which is an autoimmune inflammatory disease. The purpose of this study is to evaluate the significance of differences in serum angiotensin converting enzyme and lysozyme levels of patients with ocular involvement of other autoimmune inflammatory and infectious diseases.

Methods: This is a prospective study involving patients with ankylosing spondylitis, behcet's disease, presumed sarcoidosis, presumed latent tuberculosis, presumed latent syphilis, and control group. The serum levels of angiotensin converting enzyme and lysozyme were analyzed by enzyme-linked immunosorbent assay. Bonnferoni analysis was used to assess pairwise comparisons between the groups.

Results: There was a significant increase in serum angiotensin converting enzyme level in patients with presumed sarcoidosis compared to ankylosing spondylitis $(p=0.0001)$, behcet's disease $(p=0.0001)$, presumed latent tuberculosis ( $p=0.0001)$, presumed latent syphilis $(p=0.0001)$, and control group $(p=0.0001)$. The increase in serum lysozyme level was significant for patients with presumed sarcoidosis with respect to ankylosing spondylitis $(p=0.0001)$, behcet's disease, $(p=0.0001)$ presumed latent tuberculosis $(p=0.001)$, presumed latent syphilis $(p=0.033)$, and control group $(p=0.0001)$.

Conclusion: Elevated serum angiotensin converting enzyme levels are significant for patients with presumed sarcoidosis compared to ocular involvement of other autoimmune diseases such as behcet's disease and ankylosing spondylitis, and ocular involvement of infectious diseases such as presumed latent tuberculosis and presumed latent syphilis. However, elevated serum lysozyme level might be also detected in ocular involvement of infectious diseases such as presumed latent tuberculosis and presumed latent syphilis.
\end{abstract}

Trial registration: Trial Registration number: NCT02627209. Date of registration: 12/09/2015.

Keywords: Angiotensin converting enzyme, Lysozyme, Ankylosing spondylitis, Behcet's disease, Sarcoidosis, Syphilis, Tuberculosis, Ocular inflammation

\footnotetext{
* Correspondence: ozlem1158@yahoo.com

${ }^{1}$ Department of Ophthalmology/Uveitis, Dunya Goz Hospital Ltd., Ankara,

Turkey

Full list of author information is available at the end of the article
} 


\section{Background}

The renin angiotensin system (RAS) is an important hormonal system which promotes inflammation through the axis of angiotensin converting enzyme (ACE)-angiotensin peptides-distinct receptor subtypes [1]. Hyperactivation of the RAS system has been disclosed to involve in inflammatory responses of the eye $[2,3]$. Increased serum ACE activity has been reported especially in uveitis associated with sarcoidosis, and also infectious uveitis such as recurrent toxoplasmic and toxocaral iridocyclitis and choroioretinitis [4, 5]. Lysozyme is an enzyme that hydrolyses glycosidic bonds, and it is revealed to degrade the peptidoglycans in the bacterial cell wall [6]. Muramidase activity of lysozyme has been shown to limit the inflammation caused by rapidly degrading peptidoglycans at the site of infection [7]. Elevated levels of serum lysozyme have been reported in granulomatous uveitis especially sarcoidosis and tuberculosis [8]. The purpose of this study is to evaluate the significance of differences in serum ACE and lysozyme levels of patients with ocular involvement of autoimmune diseases such as $\mathrm{HLAB}_{2} 7^{+}$ankylosing spondylitis (AS), $\mathrm{HLAB}^{+} 1^{+}$behcet's disease (BD) and presumed sarcoidosis and ocular involvement of infectious diseases such as QuantiFERON $\left({ }^{\circ}\right)$-TB Gold $^{+}$presumed latent tuberculosis (TB) and presumed latent syphilis compared to control group by using pairwise comparisons between the groups.

\section{Methods}

\section{Study patients}

This is a prospective study involving 76 patients with AS, 72 patients with $\mathrm{BD}, 31$ patients with presumed sarcoidosis, and 68 patients with presumed latent TB, 11 patients with presumed latent syphilis, and 22 control subjects having refractive errors only. Institutional review board/ethics committee approval was obtained from the Dunya Goz Hospital Institutional Board (DGH-070) Ankara, Turkey. This study adhered to the tenets of the Declaration of Helsinki. The written informed consent was obtained for all individuals who enrolled in this study. The patients had ocular manifestations including acute or chronic granulomatous or non-granulomatous iritis or iridocyclitis, intermediate, posterior or panuveitis, retinitis, retinal vasculitis, choroiditis and papillitis. The uveitis was not always granulomatous inside the the group of presumed ocular sarcoidosis. The international criteria for the diagnosis of presumed ocular sarcoidosis and international study criteria for BD were used $[9,10]$. Inclusion criteria for all patients involve the presence of ocular signs associated with a positive test for HLAB27 for patients with AS, a positive test for HLAB51 for the patients with $\mathrm{BD}$, a negative tuberculin skin test in BCG-vaccinated patients, positive findings on chest $\mathrm{x}$-ray or chest $\mathrm{CT}$ or abnormal results on whole body Gallium 67 scintigraphy for the patients with presumed sarcoidosis, a positive test for QuantiFERON $\left({ }^{\circ}\right)$-TB Gold In-Tube (Cellestis limited, Melbourne, Australia) and a positive tuberculin skin test for the patients with presumed latent TB. Presumed latent syphilis was diagnosed on the basis of negative serum venereal disease research laboratory test (VDRL) and rapid plasma reagin test, (RPR) positive serum fluorescent treponemal antibody absorption (FTAABS) and microhemagglutination assay for Treponema pallidum, (MHATP), negative cerebrospinal fluid (CSF) FTAABS, and improvement in level of ocular inflammation after treatment with specific therapy for syphilis [11]. The difference in the levels of ACE in granulomatous and a nongranulomatous groups were not compared. The connection of increased serum lysozyme levels between systemic diseases such as sarcoidosis was not studied. The exclusion criteria for the patient and control groups were using ACE inhibitors, systemic steroids, immunosuppressive or immunomodulatory therapies.

\section{Blood sampling}

Blood samples were collected from the patients by using a standard aseptic technique. Native blood was incubated for $60 \mathrm{~min}$ at room temperature; serum fractions (separated by centrifugation at $1500 \mathrm{~g}$ for $15 \mathrm{~min}$ ) were stored at $-20{ }^{\circ} \mathrm{C}$.

\section{Serum ACE activity measurement using spectrophotometric assay}

Serum ACE activity was measured as described by Beneteau et al [12]. ACE activity was determined with an artificial substrate (FAPGG, ( $N$-[3-(2-furyl) acryloyl]-L-phenylalanyl-glycylglycine; Sigma-Aldrich) in a reaction mixture containing $25 \mathrm{mM}$ HEPES ( $N$-2-hydroxyethylpiperazine- $N$-2-ethanesulfonic acid), 0.5 mM FAPGG, $300 \mathrm{mM} \mathrm{NaCl}$, and the desired dilution of serum at pH 8.2. Measurements were performed in 96-well plates (Greiner-Bio One) at $37^{\circ} \mathrm{C}$. Changes in optical density $(340 \mathrm{~nm})$ were measured at 5-min intervals for at least 90 min with a plate reader (NovoStar plate reader; BMG Labtech). Optical density values were plotted as a function of reaction time and fitted by linear regression (GraphPad Prism 5.0). The fit and the data were accepted when $r^{2}$ was $>0.90$. ACE activity was calculated with the equation:

$$
\text { activity }=(S / k) D
$$

where $\mathrm{S}$ is the rate of observed decrease in optical density $(1 / \mathrm{min}), \mathrm{k}$ is the change in optical density upon the complete cleavage of $1 \mu \mathrm{mol}$ of FAPGG, and D is the dilution of the serum. ACE activity is given in units where $1 \mathrm{U}$ is equivalent to the cleavage of $1 \mu \mathrm{mol}$ of FAPGG in $1 \mathrm{~min}$. The reference range for serum ACE level was between 8 
and $52 \mathrm{U} / \mathrm{L}$ for adults, and between 13 and $100 \mathrm{U} / \mathrm{L}$ for children less than 18 years of age.

\section{Serum lysozyme activity measurement using radial immunodiffusion}

Serum lysozyme activity was measured by using radial immunodiffusion as described by Mancini G. et al. [13]. Human 'NL' Nanorid plate, No GT073.3, (Binding Site Ltd., Birmingham, UK) and lysozyme - NL 2.1-21* GT073.3 NANORID ${ }^{\mathrm{Tm}}$ kits (Binding Site Ltd., Birmingham, UK) were used. The precipitation ring diameters were measured using Digital Rid Plate Reader. (Binding Site Ltd., Birmingham, UK) The reference range for serum lysozyme was between 9.6 and $16.8 \mathrm{mg} / \mathrm{L}$ for all age groups.

\section{Statistical analysis}

Statistical analysis was performed by using SPSS for Windows 13.0.1 (SPSS Inc., Chicago, IL, USA) statistical software products. All results were expressed as mean \pm SD. All statistical analyses were performed two-tailed and $p<0.05$ was considered as significant. One-way ANOVA and Tukey's tests were used for age distribution, and Chi Square test is used for sex distribution. Multivariate analysis of covariance was used to determine the significance of differences in serum levels of ACE and lysozyme with age as the covariate. Bonnferoni analysis was used to assess pairwise comparisons between the groups.

\section{Results}

\section{Demographics of the patient and control groups}

The age range, mean, standard deviation (SD), and the lower and upper bounds of $95 \%$ confidence interval (CI) values for mean values of age for patients with AS, $\mathrm{BD}$, presumed sarcoidosis, presumed latent $\mathrm{TB}$, presumed latent syphilis, and control group were shown in Table 1 . The age range of total 280 subjects was between 9 and 86 with a mean (SD) of 42.892 (16.013). The mean
(SD) ages of patients with AS, BD, presumed sarcoidosis, presumed latent TB, presumed latent syphilis and control group were 41.868 (12.536), 38.277 (14.681), 41.000 (18.954), 52.735 (15.525), 44.272 (14.553), and 33.090 (15.377) years respectively (Table 1 ). The sex distribution and percentages within the groups were shown in Table 2. The total of 280 subjects 139 (49.6\%) were female and 141 (50.4\%) were male. The sex distribution and percentages of the patients with $\mathrm{AS}, \mathrm{BD}$, presumed sarcoidosis, presumed latent $\mathrm{TB}$, presumed latent syphilis, and control group were 35 (46.10\%) female and 41 (53.9) male, 43 (59.7\%) female and 29 (40.3 \%) male, 13 (41.9\%) female and 18 (58.1\%) male, 36 (52.9\%) female and $32(47.1 \%)$ male, 4 (36.4\%) female and 7 (63.6 \%) male, and 8 (36.4 \%) female and 14 (63.6 \%) male respectively (Table 2 ).

\section{Serum ACE and lysozyme activities of the patient and control groups}

The mean (SD) values of serum ACE and lysozyme levels of the patients with AS, BD, presumed sarcoidosis, presumed latent $\mathrm{TB}$, presumed latent syphilis and control group were shown in Table 3 . The mean (SD) values of serum ACE for patients with AS, BD, presumed sarcoidosis, presumed latent $\mathrm{TB}$, presumed latent syphilis and control group were 29.363 (2.012), 31.227 (15.225), 58.164 (35.110), 33.061 (15.065), 30.527 (16.016) and 20.704 (7.962) U/L respectively (Table 3 ). The estimated marginal means of serum ACE levels in groups were disclosed in Fig. 1. According to this graph, the lowest value for the estimated marginal mean of serum ACE level is $21.251 \mathrm{U} / \mathrm{L}$ for control group, and the highest value is $58.274 \mathrm{U} / \mathrm{L}$ for the patients with presumed sarcoidosis. The estimated marginal mean values of serum ACE level for the patients with AS, BD, presumed latent TB and presumed latent syphilis were 29.360, $31.392,32.500$ and $30.452 \mathrm{U} / \mathrm{L}$ respectively which were lower than the estimated marginal mean value of ACE for presumed sarcoidosis, but higher than the estimated

Table 1 The sample size, age range, mean value, standard deviation, the lower and upper bounds of $95 \%$ confidence interval for mean age of the patients with ocular involvement of ankylosing spondylitis, behcet's disease, presumed sarcoidosis, presumed latent tuberculosis, presumed latent syphilis and control group

\begin{tabular}{llllllll}
\hline Groups & $\mathrm{n}$ & Min age & Max age & Mean age & $\mathrm{SD}$ & $95 \% \mathrm{Cl}$ for Mean Lower Bound & $95 \%$ Cl for Mean Upper Bound \\
\hline AS & 76 & 15 & 74 & 41.868 & 12.536 & 37.003 & 44.733 \\
BD & 72 & 9 & 75 & 38.277 & 14.681 & 34.827 & 41.727 \\
P. Sarcoidosis & 31 & 10 & 72 & 41.000 & 18.954 & 34.047 & 47.952 \\
TB & 68 & 21 & 86 & 52.735 & 15.525 & 48.977 & 56.493 \\
P. Syphilis & 11 & 22 & 67 & 44.272 & 14.553 & 34.495 & 54.050 \\
Control & 22 & 12 & 68 & 33.090 & 15.377 & 26.272 & 39.908 \\
Total & 280 & 9 & 86 & 42.892 & 16.013 & 41.009 & 44.776 \\
\hline
\end{tabular}

$n$ Sample size, Min minimum, Max maximum, SD standard deviation, $C l$ confidence interval, $A S$ ankylosing spondylitis, $B D$ behcet's disease, $T B$ presumed latent tuberculosis, P. Sarcoidosis presumed sarcoidosis, P. Syphilis presumed latent syphilis 
Table 2 The sex distribution and sample size of patients with ocular involvement of ankylosing spondylitis, behcet's disease, presumed sarcoidosis and presumed latent tuberculosis, presumed latent syphilis and control group

\begin{tabular}{llll}
\hline Groups & Female & Male & $\mathrm{n}$ \\
\hline AS & $35(46.1 \%)$ & $41(53.9 \%)$ & 76 \\
BD & $43(59.7 \%)$ & $29(40.3 \%)$ & 72 \\
P. Sarcoidosis & $13(41.9 \%)$ & $18(58.1 \%)$ & 31 \\
TB & $36(52.9 \%)$ & $32(47.1 \%)$ & 68 \\
P. Syphilis & $4(36.4 \%)$ & $7(63.6 \%)$ & 11 \\
Control & $8(36.4 \%)$ & $14(63.6 \%)$ & 22 \\
Total & $139(49.6)$ & $141(50.4)$ & 280 \\
\hline
\end{tabular}

$n$ sample size, $A S$ ankylosing spondylitis, $B D$ behcet's disease, $T B$ presumed latent tuberculosis, P. Sarcoidosis presumed sarcoidosis, P. Syphilis presumed latent syphilis

marginal mean value of ACE for control group (Fig. 1). The mean (SD) values of serum lysozyme level for patients with AS, BD, presumed sarcoidosis, presumed latent TB, presumed latent syphilis and control group were 14.096 (4.586), 14.244 (5.358), 20.712 (6.780), 15.259 (8.516), 14.018 (6.679) and 12.927 (4.720) $\mathrm{mg} / \mathrm{L}$ respectively (Table 3 ). The estimated marginal means of serum lysozyme levels in groups were disclosed in Fig. 2. According to this graph, the lowest value for the estimated marginal mean of serum lysozyme level was $13.200 \mathrm{mg} / \mathrm{L}$

Table 3 The sample size, mean value, standard deviation of serum angiotensin converting enzyme levels of the patients with ocular involvement of ankylosing spondylitis, behcet's disease, presumed sarcoidosis, presumed latent tuberculosis, presumed latent syphilis and control group

\begin{tabular}{lllll}
\hline Groups & $\begin{array}{c}\text { Mean } \\
\text { value }\end{array}$ & SD & $\begin{array}{l}95 \% \mathrm{Cl} \\
\text { Lower bound }\end{array}$ & $\begin{array}{c}95 \% \mathrm{Cl} \\
\text { Upper bound }\end{array}$ \\
\hline Serum ACE Level (U/L) & & & & \\
AS & 29.363 & 2.012 & 25.403 & 33.324 \\
BD & 31.486 & 2.091 & 27.369 & 35.603 \\
P. Sarcoidosis & 58.270 & 3.151 & 52.067 & 64.472 \\
TB & 32.504 & 2.254 & 28.066 & 36.942 \\
P. Syphilis & 30.449 & 5.285 & 20.044 & 40.854 \\
Control & 21.254 & 3.800 & 13.772 & 28.736 \\
Serum Lysozyme Level & & & & \\
(mg/L) & & & & \\
AS & 14.124 & 0.718 & 12.710 & 15.538 \\
BD & 14.371 & 0.747 & 12.901 & 15.841 \\
P. Sarcoidosis & 20.765 & 1.125 & 18.550 & 22.979 \\
TB & 14.987 & 0.805 & 13.402 & 16.571 \\
P. Syphilis & 13.980 & 1.887 & 10.265 & 17.695 \\
Control & 13.196 & 1.357 & 10.525 & 15.868
\end{tabular}

$A C E$ angiotensin converting enzyme, $A S$ ankylosing spondylitis, $B D$ behcet's disease, $\mathrm{Cl}$ confidence interval, TB presumed latent tuberculosis, $P$. Sarcoidosis presumed sarcoidosis, $P$. Syphilis presumed latent syphilis, $S D$ standard deviation for control group, and the highest value was $20.776 \mathrm{mg} / \mathrm{L}$ for patients with presumed sarcoidosis. The estimated means of serum lysozyme levels of patients with AS, BD, presumed latent $\mathrm{TB}$ and presumed latent syphilis were $14.122,14.374,14.998$ and $13.989 \mathrm{mg} / \mathrm{L}$ respectively which were lower than the estimated marginal mean value of lysozyme for presumed sarcoidosis, and higher than the estimated marginal mean value of serum lysozyme for control group (Fig. 2).

\section{Pairwise comparisons of the mean differences of serum ACE levels between groups}

The mean (SD) differences of serum ACE levels between the patients with presumed sarcoidosis and AS, BD, presumed latent TB, presumed latent syphilis and control group were 28.907 (3.735), 26.784 (3.770), 25.776 (3.898), 27.821 (6.155), and 37.016 (4.918) U/L respectively. (Table 4) The increase in serum ACE level was significant for patients with presumed sarcoidosis compared to patients with $\mathrm{AS}(p=0.0001), \mathrm{BD}(p=0.0001)$, presumed latent TB $(p=$ $0.0001)$, presumed latent syphilis $(p=0.0001)$, and control group $(p=0.0001)$. The mean (SD) differences of serum ACE levels between control group and AS, BD, presumed latent $\mathrm{TB}$, presumed latent syphilis were -8.110 (4.288), -10.232 (4.285), -11.250 (4.528), and -9.195 (6.520) respectively (Table 4). There were no significant differences of serum ACE levels between control group and $\mathrm{AS}(p=0.895)$, control group and $\mathrm{BD}(p=0.264)$, control group and TB, $(p=0.204)$ control group and presumed latent syphilis. $(p=1.000)$ (Table 4$)$ Pairwise comparison of mean (SD) difference of serum ACE level between AS and BD was -2.123 (2.894), between AS and presumed latent TB was -3.141 (3.038), between AS and presumed latent syphilis was -1.086 (5.656), between $\mathrm{BD}$ and presumed latent TB was -1.018 (3.149), between $\mathrm{BD}$ and presumed latent syphilis was 1.037 (5.689), and between presumed latent TB and presumed latent syphilis was 2.055 (5.734) respectively (Table 4). No significant differences of serum ACE levels revealed between AS and $\mathrm{BD}(p=0.689)$, between AS and presumed latent TB $(p=1.000)$, between AS and presumed latent syphilis $(p=0.996)$, between $\mathrm{BD}$ and presumed latent TB $(p=1.000)$, between $\mathrm{BD}$ and presumed latent syphilis $(p=$ $0.817)$, and between presumed latent TB and presumed latent syphilis $(p=0.504)$, (Table 4$)$.

\section{Pairwise comparisons of the mean differences of serum lysozyme levels between groups}

The mean (SD) differences of serum lysozyme levels between patients with presumed sarcoidosis and AS, BD, presumed latent $\mathrm{TB}$, presumed latent syphilis and control group were 6.641 (1.334), 6.394 (1.346), 5.778 (1.392), 6.785 (2.198), and $7.568(1.756) \mathrm{mg} / \mathrm{L}$ respectively (Table 5). The increase in serum lysozyme level was 


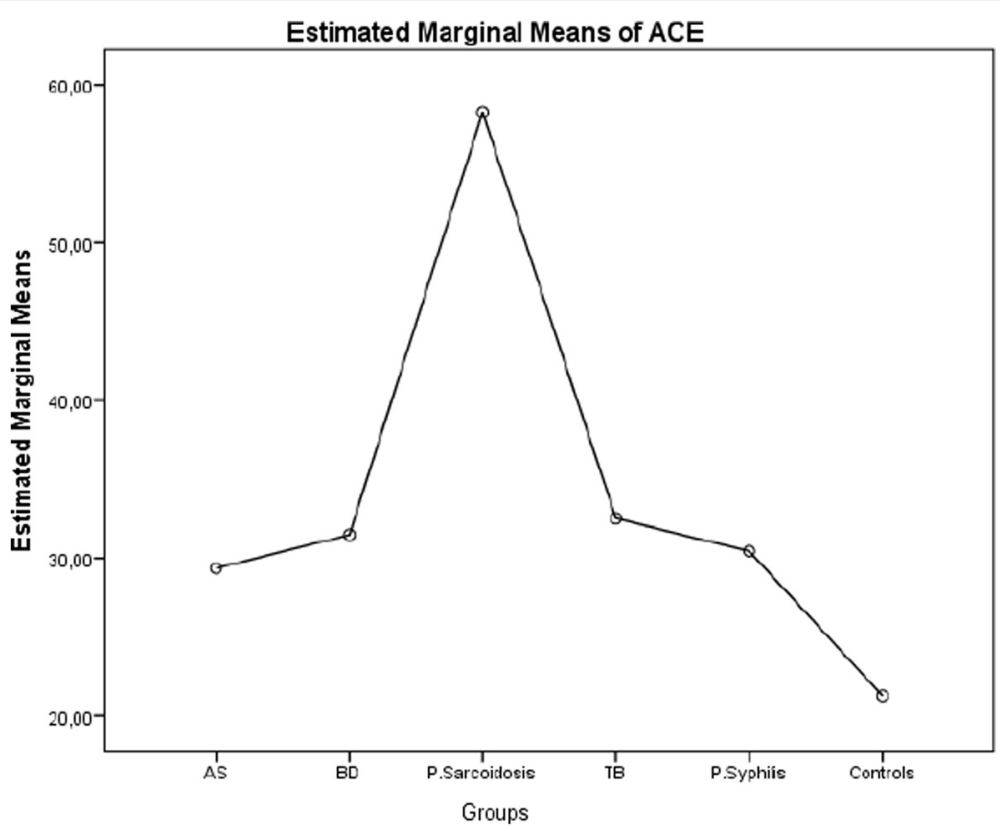

Fig. 1 The estimated marginal means of serum angiotensin converting enzyme levels of patients with ocular involvement of ankylosing spondylitis, behcet's disease, presumed sarcoidosis, presumed latent tuberculosis, presumed latent syphilis and control group

significant for patients with presumed sarcoidosis with respect to $\operatorname{AS}(p=0.0001), \mathrm{BD}(p=0.0001)$, presumed latent TB $(p=0.001)$, presumed latent syphilis $(p=0.033)$, and control group $(p=0.0001)$ (Table 5) The mean (SD) differences of serum lysozyme levels between control group and $\mathrm{AS}, \mathrm{BD}$, presumed latent $\mathrm{TB}$, presumed latent syphilis were $-0.928(1.531),-1.175(1.530),-1.790$ (1.617), and -0.784 (2.328) respectively (Table 5). There were no significant differences of serum lysozyme levels between control group and AS $(p=1.000)$, control group and $\mathrm{BD}(p=1.000)$ control group and presumed latent TB $(p=1.000)$, control group and presumed latent syphilis

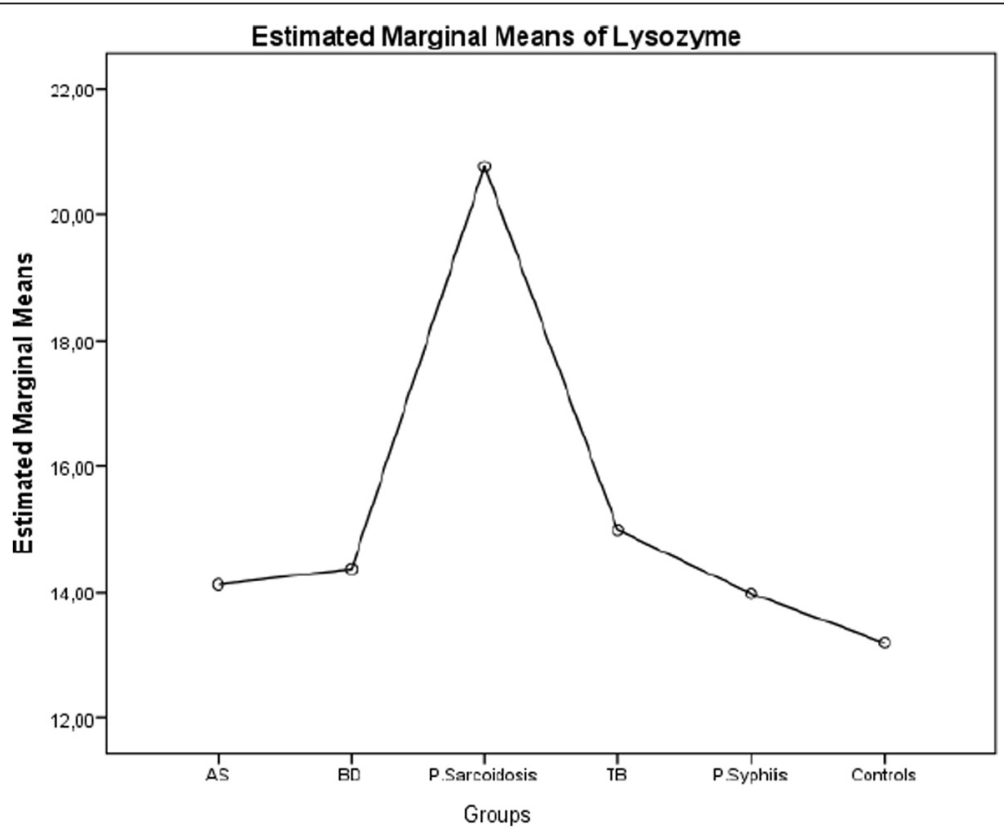

Fig. 2 The estimated marginal means of serum lysozyme levels of patients with ocular involvement of ankylosing spondylitis, behcet's disease, presumed sarcoidosis, presumed latent tuberculosis, presumed latent syphilis and control group 
Table 4 Pairwise comparison of the mean difference values of serum angiotensin converting enzyme levels of the patients with ocular involvement of ankylosing spondylitis, behcet's disease, presumed sarcoidosis, presumed latent tuberculosis, presumed latent syphilis and control group

\begin{tabular}{|c|c|c|c|c|c|}
\hline Pairwise Comparison & Mean Difference & Standard Deviation & $\mathrm{Sig}^{\mathrm{b}}$ & 95 \% Cl Lower Bound & 95 \% Cl Upper Bound \\
\hline$A S-B D$ & -2.123 & 2.894 & 0.689 & -10.691 & 6.446 \\
\hline AS - P. Sarcoidosis & -28.907 & 3.735 & 0.0001 & -39.969 & -17.845 \\
\hline$A S-T B$ & -3.141 & 3.038 & 1.000 & -12.137 & 5.856 \\
\hline AS - P. Syphilis & -1.086 & 5.656 & 0.996 & -17.836 & 15.665 \\
\hline AS - Control & 8.110 & 4.288 & 0.895 & -4.590 & 20.809 \\
\hline$B D-A S$ & 2.123 & 2.894 & 0.689 & -6.446 & 10.691 \\
\hline BD - P. Sarcoidosis & -26.784 & 3.770 & 0.0001 & -37.948 & -15.620 \\
\hline$B D-T B$ & -1.018 & 3.149 & 1.000 & -10.343 & 8.306 \\
\hline BD - P. Syphilis & 1.037 & 5.689 & 0.817 & -15.812 & 17.885 \\
\hline BD - Control & 10.232 & 4.285 & 0.264 & -2.458 & 22.922 \\
\hline P. Sarcoidosis - AS & 28.907 & 3.735 & 0.0001 & 17.845 & 39.969 \\
\hline P. Sarcoidosis - BD & 26.784 & 3.770 & 0.0001 & 15.620 & 37.948 \\
\hline P. Sarcoidosis - TB & 25.766 & 3.898 & 0.0001 & 14.222 & 37.310 \\
\hline P. Sarcoidosis-P. Syphilis & 27.821 & 6.155 & 0.0001 & 9.593 & 46.048 \\
\hline P. Sarcoidosis-Control & 37.016 & 4.918 & 0.0001 & 22.453 & 51.580 \\
\hline TB - AS & 3.141 & 3.038 & 1.000 & -5.856 & 12.137 \\
\hline $\mathrm{TB}-\mathrm{BD}$ & 1.018 & 3.149 & 1.000 & -8.306 & 10.343 \\
\hline TB - P. Sarcoidosis & -25.766 & 3.898 & 0.0001 & -37.310 & 14.222 \\
\hline TB - P. Syphilis & 2.055 & 5.734 & 0.504 & -14.925 & 19.095 \\
\hline TB - Control & 11.250 & 4.528 & 0.204 & -2.159 & 24.660 \\
\hline P. Syphilis - AS & 1.086 & 5.656 & 0.996 & -6.124 & 5.837 \\
\hline P. Syphilis - BD & -1.037 & 5.689 & 0.817 & -17.885 & 15.812 \\
\hline P. Syphilis-P. Sarcoidosis & -27.821 & 6.155 & 1.000 & -19.035 & 14.925 \\
\hline P. Syphilis - Control & 9.195 & 6.520 & 1.000 & -10.113 & 28.504 \\
\hline Control - AS & -8.110 & 4.288 & 0.895 & -20.809 & 4.590 \\
\hline Control - BD & -10.232 & 4.285 & 0.264 & -22.922 & 2.458 \\
\hline Control -P. Sarcoidosis & -37.016 & 4.918 & 0.0001 & -51.580 & -22.453 \\
\hline Control - TB & -11.250 & 4.528 & 0.204 & 24.660 & 2.159 \\
\hline Control - P. Syphilis & -9.195 & 6.520 & 1.000 & -28.504 & 10.113 \\
\hline
\end{tabular}

The mean difference is significant at the 0.05 level

Sigb Adjustment for multiple comparisons Bonferroni, DV Dependent variable, $A C E$ Angiotensin converting enzyme, $A S$ ankylosing spondylitis, $B D$ behcet's disease, $T B$ presumed latent tuberculosis, $P$. Sarcoidosis presumed sarcoidosis, $P$. Syphilis presumed latent syphilis

$(p=1.000)$ (Table 5). Pairwise comparison of mean (SD) difference of serum lysozyme level between AS and BD was -0.247 (1.033), between AS and presumed latent TB was -0.863 (1.085), between AS and presumed latent syphilis was $0.144(2.020)$, between BD and presumed latent TB was -0.616 (1.124), between BD and presumed latent syphilis was 0.391 (2.031), and between presumed latent TB and presumed latent syphilis was 1.007 (2.047) (Table 5). There were no significant differences of serum lysozyme levels between AS and $\mathrm{BD}(p=$ 1.000), between $\mathrm{AS}$ and presumed latent $\mathrm{TB}(p=1.000)$, between AS and presumed latent syphilis $(p=1.000)$, between $\mathrm{BD}$ and presumed latent TB $(p=1.000)$, between
$\mathrm{BD}$ and presumed latent syphilis $(p=1.000)$, and between presumed latent TB and presumed latent syphilis $(p=$ 1.000) (Table 5).

\section{Discussion}

Previous studies have demonstrated the correlations of serum levels of inflammatory chemokines and cytokines with serum ACE and lysozyme activities in patients with ocular and pulmonary sarcoidosis $[14,15]$. Chemokine (C-X-C motif) ligand 9 (CXCL9), also known as monokine induced by gamma interferon, (MIG) and C-X-C motif chemokine 10 (CXCL10) also known as interferon gamma-induced protein 10 (IP-10) have been reported 
Table 5 Pairwise comparison of the mean difference values of serum lysozyme levels of the patients with ocular involvement of ankylosing spondylitis, behcet's disease, presumed sarcoidosis, presumed latent tuberculosis, presumed latent syphilis and control group

\begin{tabular}{|c|c|c|c|c|c|}
\hline Pairwise Comparison & Mean Difference & Standard Deviation & Sig.b & $95 \%$ Cl Lower Bound & 95 \% Cl Upper Bound \\
\hline$A S-B D$ & -0.247 & 1.033 & 1.000 & -3.306 & 2.812 \\
\hline AS - P. Sarcoidosis & -6.641 & 1.334 & 0.0001 & -10.590 & -2.691 \\
\hline AS - TB & -0.863 & 1.085 & 1.000 & -4.075 & 2.349 \\
\hline AS - P. Syphilis & 0.144 & 2.020 & 1.000 & -5.837 & 6.124 \\
\hline AS - Control & 0.928 & 1.531 & 1.000 & -3.607 & 5.462 \\
\hline$B D-A S$ & 0.247 & 1.033 & 1.000 & -2.812 & 3.306 \\
\hline BD - P. Sarcoidosis & -6.394 & 1.346 & 0.0001 & -10.380 & -2.408 \\
\hline$B D-T B$ & -0.616 & 1.124 & 1.000 & -3.945 & 2.713 \\
\hline BD - P. Syphilis & 0.391 & 2.031 & 1.000 & -5.625 & 6.407 \\
\hline BD - Control & 1.175 & 1.530 & 1.000 & -3.356 & 5.705 \\
\hline P. Sarcoidosis - AS & 6.641 & 1.334 & 0.0001 & 2.691 & 10.590 \\
\hline P. Sarcoidosis - BD & 6.394 & 1.346 & 0.0001 & 2.408 & 10.380 \\
\hline P. Sarcoidosis - TB & 5.778 & 1.392 & 0.001 & 1.656 & 9.900 \\
\hline P. Sarcoidosis-P. Syphilis & 6.785 & 2.198 & 0.033 & 0.277 & 13.293 \\
\hline P. Sarcoidosis - Control & 7.568 & 1.756 & 0.0001 & 2.369 & 12.768 \\
\hline TB - AS & 0.863 & 1.085 & 1.000 & -2.349 & 4.075 \\
\hline$T B-B D$ & 0.616 & 1.124 & 1.000 & -2.713 & 3.945 \\
\hline TB - P. Sarcoidosis & -5.778 & 1.392 & 0.001 & -9.900 & -1.656 \\
\hline TB - P. Syphilis & 1.007 & 2.047 & 1.000 & -5.056 & 7.069 \\
\hline TB - Control & 1.790 & 1.617 & 1.000 & -2.997 & 6.578 \\
\hline P. Syphilis - AS & -0.144 & 2.020 & 1.000 & -6.124 & 5.837 \\
\hline P. Syphilis - BD & -0.391 & 2.031 & 1.000 & -6.407 & 5.625 \\
\hline P. Syphilis - P. Sarcoidosis & -6.785 & 2.198 & 0.033 & -13.293 & -0.277 \\
\hline P. Syphilis - TB & -1.007 & 2.047 & 1.000 & -7.069 & 5.056 \\
\hline P. Syphilis - Control & 0.784 & 2.328 & 1.000 & -6.110 & 7.678 \\
\hline Control - AS & -0.928 & 1.531 & 1.000 & -5.462 & 3.607 \\
\hline Control - BD & -1.175 & 1.530 & 1.000 & -5.705 & 3.356 \\
\hline Control - P. Sarcoidosis & -7.568 & 1.756 & 0.0001 & -12.768 & -2.369 \\
\hline Control - TB & -1.790 & 1.617 & 1.000 & -6.578 & 2.997 \\
\hline Control - P. Syphilis & -0.784 & 2.328 & 1.000 & -7.678 & 6.110 \\
\hline
\end{tabular}

The mean difference is significant at the 0.05 level

Sigb Adjustment for multiple comparisons Bonferroni, $C l$ Confidence Interval, ACE Angiotensin converting enzyme, $A S$ ankylosing spondylitis, $B D$ behcet's disease, TB presumed latent tuberculosis, $P$. Sarcoidosis presumed sarcoidosis, $P$. Syphilis presumed latent syphilis

to induce the recruitment of activated T helper (Th1) cells $[16,17]$. Serum levels of CXCL9 and CXCL10 have been correlated with serum ACE levels in presumed ocular sarcoidosis [15]. Interleukin 12 (IL-12) p40, an essential component of IL-12 has been reported to induce differentiation of naïve Th cells into Th1 cells [15]. Serum concentrations of IL-12 p40 have been found significantly higher in pulmonary sarcoidosis than healthy subjects and have been correlated with serum levels of ACE and lysozyme [18]. This study compares for the first time the serum ACE and lysozyme levels of patients diagnosed with ocular involvement of autoimmune diseases such as AS, BD and presumed sarcoidosis and ocular involvement of infectious diseases such as presumed latent TB and presumed latent syphilis. Intraocular inflammation compatible with sarcoidosis associated with elevated serum ACE levels is considered suggestive for diagnosis of presumptive sarcoidosis in patients without having a tissue biopsy $[16,17,19-21]$. The serum ACE level is disclosed higher in children than in adults [21]. The World Association of Sarcoidosis and Other Granulomatous disorders (WASOG) considered an increased ACE might help in diagnosis of sarcoidosis in children [22]. The age range in sarcoidosis group in our study is between 10 and 72 with a mean age of 41 . The estimated mean level of serum ACE of our patients with 
presumed sarcoidosis is $58.274 \mathrm{IU} / \mathrm{L}$ which is above the normal adult range of 8-52 IU/L. Serum ACE level has been compared between patients having sarcoidosis and sarcoidosis-like lung diseases including $\mathrm{TB}$, fibrosing alveolitis, histiocytosis $\mathrm{X}$, and pneumoconiosis [23]. Rise of serum ACE activity has been found in $93 \%$ of patients with active sarcoidosis, $41 \%$ of patients with TB and $56 \%$ of patients with nonspecific inflammatory lung diseases including fibrosing alveolitis, histiocytosis X, and pneumoconiosis [23]. Serum ACE level has not been studied before in the ocular involvement of presumed latent TB. Our study revealed the estimated marginal mean of serum ACE level in patients with presumed latent TB as $32.500 \mathrm{U} / \mathrm{L}$. Pairwise comparison of serum ACE levels between patients with presumed latent TB and presumed sarcoidosis disclosed a statistically significant difference for patients with presumed sarcoidosis with respect to presumed latent TB $(p=0.0001)$. There was also no significant difference of elevated serum ACE levels between patients with presumed latent TB and control group $(p=0.204)$.

The serum activity of ACE has been compared for patients with BD, Vogt-Koyanagi-Harada's disease and sarcoidosis [24]. Significant elevation of serum ACE activity has been observed only for patients with sarcoidosis [24]. Our study revealed the estimated marginal mean of serum ACE level for patients with BD as $31.392 \mathrm{U} / \mathrm{L}$. A significant elevation of serum ACE level in patients with presumed sarcoidosis with respect to BD has been disclosed in our study $(p=0.0001)$. Serum levels of ACE activity have been compared in patients with rheumatoid arthritis, osteoarthritis, ankylosing spondylitis, psoriatic arthritis and BD, and no statistically significant differences have been found from those of normal controls [25]. The serum ACE activity has not been investigated in HLAB27 positive AS related uveitis. Our study disclosed the estimated marginal mean of serum ACE level in patients with AS as $29.363 \mathrm{U} / \mathrm{L}$. Our study revealed a statistically significant difference in serum ACE level for patients with presumed sarcoidosis compared to patients with AS ( $p=$ 0.0001). No significant difference of elevated serum ACE levels was found between AS and control group. ( $p=$ 1.000) Elevated serum lysozyme levels have been included in the criteria for diagnosis of ocular sarcoidosis [26]. The serum levels of ACE and lysozyme have been reported increased in 40 and $42 \%$ of patients with biopsy-proven ocular sarcoidosis respectively [27]. The levels of at least one of the serum markers ACE and lysozyme were found elevated in $58 \%$ of patients with biopsy-proven sarcoidosis [27]. The estimated marginal means of serum ACE and lysozyme levels for the patients with AS, BD, presumed sarcoidosis, presumed latent TB, presumed latent syphilis and control group disclosed on Graph 1 and Graph 2 in our study have similar curves with minimum values for control group and maximum values for presumed sarcoidosis. The sensitivity of serum lysozyme for predicting sarcoidosis was reported as $79.1 \%$ and the sensitivity of serum ACE for predicting sarcoidosis was reported as $59 \%$ [28]. However, the specificity of serum lysozyme level has been reported to be less for sarcoidosis than serum ACE level, and it has been considered that the diagnostic value of serum lysozyme for sarcoidosis might be limited [28]. In another study considering the predictive value of serum ACE and lysozyme levels in diagnosis of ocular sarcoidosis, the sensitivity of increased serum ACE level was found as $84 \%$, specificity was $95 \%$, and predictivity was $47 \%$. However, the sensitivity of increased serum lysozyme levels was $60 \%$, specificity was $76 \%$, and spredictivity was $12 \%$ [29]. Both studies showed that increased serum lysozyme levels might be less predictive for ocular sarcoidosis. Our study revealed the estimated marginal means of serum lysozyme for patients with AS, $\mathrm{BD}$, presumed sarcoidosis, presumed latent $\mathrm{TB}$, presumed latent syphilis and control group as 14.124, 14.371, 20.765,14.987, 13.980, and $13.196 \mathrm{mg} / \mathrm{L}$ respectively. Pairwise comparisons of the serum lysozyme levels between patients with presumed sarcoidosis and AS and BD revealed statistically significant differences for presumed sarcoidosis ( $p=0.0001$ and $p=0.0001$ respectively). Pairwise comparison of the serum lysozyme levels between patients with presumed sarcoidosis and presumed latent TB revealed a statistically significant difference for sarcoidosis with the $p$ value 0.001 which was greater than the $p$ value of pairwise comparison of the serum ACE levels between patients with presumed sarcoidosis and presumed latent TB. Pairwise comparison of the serum lysozyme levels between the patients with presumed sarcoidosis and presumed latent syphilis revealed a statistically significant difference for presumed sarcoidosis with the $p$ value 0.033 which was also greater than the $\mathrm{p}$ value of pairwise comparison of the serum ACE levels between patients with presumed sarcoidosis and presumed latent syphilis. Our study disclosed that increase in serum lysozyme levels is more significant than increase in serum ACE levels for patients with infectious uveitis such as presumed latent TB and presumed latent syphilis. This study also revealed that the increase in serum lysozyme levels is less specific than increase in serum ACE levels for presumed sarcoidosis, and elevated serum lysozyme levels might be much more commonly detected in infectious uveitis such as presumed latent TB and presumed latent syphilis than autoimmune uveitis such as AS and BD.

\section{Conclusions}

Elevated serum ACE levels are significant for patients with presumed sarcoidosis compared to ocular involvement of other autoimmune diseases such as BD and AS, and ocular involvement of infectious diseases such as 
presumed latent TB and presumed latent syphilis. However, elevated serum lysozyme levels might be also detected in ocular involvement of infectious diseases such as presumed latent TB and presumed latent syphilis.

\section{Abbreviations}

ACE: angiotensin converting enzyme; AS: ankylosing spondylitis; BD: behcet's disease; Cl: confidence interval; CSF: cerebrospinal fluid; CXCL: chemokine; $D$ : dilution of the serum. ACE activity is given in units where $1 \mathrm{U}$ is equivalent to the cleavage of 1 umol of FAPGG in 1 min; FAPGG: N-[3-(2-furyl) acryloyl]-Lphenylalanyl-glycylglycine; FTAABS: fluorescent treponemal antibody absorption; IP: interferon gamma-induced protein; $\mathrm{k}$ : change in optical density upon the complete cleavage of 1 umol of FAPGG; MHA-TP: microhemagglutination assay for Treponema pallidum; RAS: renin angiotensin system; RPR: rapid plasma reagin; S: rate of observed decrease in optical density; SD: standard deviation; Th: T helper; VDRL: venereal disease research laboratory test; WASOG: World Association of Sarcoidosis and Other Granulomatous disorders.

\section{Competing interests}

The authors declare that they have no competing interests.

\section{Authors' contributions}

OS carried out the clinical examinations, diagnosis, treatment and follow-up the patients. AZ participated in design and coordination of the study. EK carried out the statistical analysis of the study. NT carried out the biochemical analysis of the sera of the patients and control groups. All authors have read and approved the final version of the manuscript.

\section{Acknowledgements}

Reha Alpar, M.D. Professor of Biostatistics, Hacettepe University Medical Faculty, for his contributions to the statistical evaluations of this study. There is no fund supporting this study.

\section{Author details}

'Department of Ophthalmology/Uveitis, Dunya Goz Hospital Ltd., Ankara, Turkey. ${ }^{2}$ Department of Ophthalmology, Boston University School of Medicine, Boston, MA, USA. ${ }^{3}$ Department of Biostatistics, Hacettepe University Medical Faculty, Ankara, Turkey. ${ }^{4}$ Department of Biochemistry, Middle East Technical University, Health Sciences, Ankara, Turkey.

Received: 19 June 2015 Accepted: 9 February 2016

Published online: 16 February 2016

\section{References}

1. Chappell MC, Marshall AC, Alzayadneh EM, Shaltout HA, Diz DI. Update on the Angiotensin Converting Enzyme 2-Angiotensin (1-7)-Mas Receptor Axis: Fetal programming, sex differences, and intracellular pathways. Front Endocrinol (Lausanne). 2014:4:201.

2. Miyazaki A, Kitaichi N, Ohgami K, Iwata D, Jin XH, Iwabuchi K, et al. Antiinflammatory effect of angiotensin type 1 receptor antagonist on endotoxin-induced uveitis in rats. Graefes Arch Clin Exp Ophthalmol. 2008;246:747-57.

3. Kurihara T, Ozawa Y, Ishida S, Okano H, Tsubota K. Renin-Angiotensin system hyperactivation can induce inflammation and retinal neural dysfunction. Int J Inflam. 2012. doi:10.1155/2012/581695.

4. Bonfiolli AA, Orefice F. Sarcoidosis. Semin Ophthalmol. 2005;20:177-82.

5. Mulak M, Misiuk-Hojlo M, Slowik M. The behavior of angiotensin converting enzyme in patients with uveitis. Klin Oczna. 1999;101:5-8.

6. Nash JA, Ballard TN, Weaver TE, Akinbi HT. The peptidoglycan degrading property of lysozyme is not required for bacteriocidal activity in vivo. J Immunol. 2006;177: 519-26.

7. Majcherczyk PA, Langen H, Heumann M, Fountoulakis M, Glauser P, Moreillion P. Digestion of Streptococcus pneumonia cell walls with its major peptidoglycan hydrolase releases branched stem peptides carrying proinflammatory activity. J Biol Chem. 1999;274:12537-43.

8. Sen DK, Sarin GS. Immunoassay of serum muramidase (lysozyme) in ocular diseases. Indian J Ophthalmol. 1987;35:103-7.

9. Herbort CP, Rao NA, Mochizuki M, members of Scientific Committee of First International Workshop on ocular sarcoidosis. International criteria for the diagnosis of ocular sarcoidosis: results of the first international Workshop on ocular sarcoidosis (IWOS). Ocul Immunol Inflamm. 2009;17:160-9.

10. [No authors listed] Evaluation of the diagnostic ('classification') criteria in Behcet's disease-towards internationally agreed criteria. The International Study Group for Behcet's disease. Br J Rheumatol 1992;31:299-308.

11. Morshed MG. Current trend on syphilis diagnosis: issues and challenges. Adv Exp Med Biol. 2014;808:51-64.

12. Beneteau B, Baudin B, Morgant G, Giboudeau J, Baumann FC. Automated kinetic assay of angiotensin-converting enzyme in serum. Clin Chem. 1986; 32:884-6.

13. Mancini $\mathrm{G}$, Carbonara $\mathrm{AO}$, Heremans JF. Immunochemical quantitation of antigens by single radial immunodiffusion. Immunochemistry. 1965;2:235-54.

14. Takeuchi M, Oh-I K, Suzuki J, Hattori D, Takeuchi A, Okunuki Y, et al. Elevated serum levels of CXCL9/monokine induced by interferon- Gamma and CXCL10/interferon gamma-inducible protein-10 in ocular sarcoidosis. Invest Ophthalmol Vis Sci. 2006;47:1063-8.

15. Trinchieri G. Interleukin-12: a cytokine produced by antigen-presenting cells with immunoregulatory functions in the generation of T-helper cells type 1 and cytotoxic lymphocytes. Blood. 1994;84:4008-27.

16. Murdoch C, Finn A. Chemokine receptors and their role in inflammation and infectious diseases. Blood. 2000;95:3032-43.

17. Gerard C, Rollins BJ. Chemokines and disease. Nat Immunol. 2001:2:108-15.

18. Ichimura $S$ et al. Increased circulating interleukin-12 (IL-12) p40 in pulmonary sarcoidosis. Clin Exp Immunol. 2003;132:152-7.

19. Stavrou P, Linton S, Young DW, Murray PI. Clinical diagnosis of ocular sarcoidosis. Eye (Lond). 1997:11:365-70.

20. Weinreb RN, O'Donnell JJ, Sandman R, Char DH, Kimura SJ. Angiotensinconverting enzyme in sarcoid uveitis. Invest Ophthalmol Vis Sci. 1979;18:1285-7.

21. Power WJ, Neves RA, Rodriquez A, Pedrosa-Seres M, Foster CS. The value of combined serum angiotensin-converting enzyme and gallium scan in diagnosing ocular sarcoidosis. Ophthalmology. 1995;102:2007-11.

22. Deverriere G, Flamans-Klein A, Firmin D, Azouzi O, Courville P, Le Roux P. Early onset pediatric sarcoidosis, diagnostic problems. Arch Pediatr. 2012;19: 707-10

23. Hunninghake GW, Costabel U, Ando M, Baughman R, Cordier JF, du Bois R, et al. ATS/ERS/WASOG statement on sarcoidosis. Sarcoidosis Vasc Diffuse Lung Dis. 1999:16:149-73.

24. Adamovich VN, Borisov SE, Zubkov AA, Danilov SM, Sakharov II, Atochina $\mathrm{EN}$. Serum angiotensin converting enzyme in the diagnosis of sarcoidosis and other lung diseases. Probl Tuberk. 1991;10:18-22.

25. Fukami R, Ohba S, Ishida K, Nakamura S, Konno M, Ohno S. Serum adenosine deaminase and angiotensin converting enzyme activity in patients with endogenous uveitis. Nihon Ganka Gakkai Zasshi. 1994;98:287-92.

26. Lowe JR, Dixon JS, Guthrie JA, McWhinney P. Serum and synovial fluid levels of angiotensin converting enzyme in polyarthritis. Ann Rheum Dis. 1986:45:921-4.

27. Tomita H, Sato S, Matsuda R, Suquira R, Kawaquichi H, Niimi T, et al. Serum lysozyme levels and clinical features of sarcoidosis. Lung. 1999;177:161-7.

28. Birnbaum AD, Oh FS, Chakrabarti A, Tessler HH, Goldstein DA. Clinical features and diagnostic evaluation of biopsy-proven ocular sarcoidosis. Arch Ophthalmol. 2011;129:409-13.

29. Baarsma GS, La Hey E, Glasius E, de Vries J, Kijlstra A. The predictive value of serum angiotensin converting enzyme and lysozyme levels in the diagnosis of ocular sarcoidosis. Am J Ophthalmol. 1987;104:211-7.

\section{Submit your next manuscript to BioMed Central and we will help you at every step:}

- We accept pre-submission inquiries

- Our selector tool helps you to find the most relevant journal

- We provide round the clock customer support

- Convenient online submission

- Thorough peer review

- Inclusion in PubMed and all major indexing services

- Maximum visibility for your research

Submit your manuscript at www.biomedcentral.com/submit 